\title{
From Studio Space and Makerspace to Workplace: Adapting Instruction and Outreach to Fit the Needs of Practitioners from Art to Engineering
}

\author{
Rebecca Kuglitsch $^{(\bowtie)}$ and Alexander Watkins \\ University Libraries, University of Colorado Boulder, Boulder, USA \\ \{Rebecca.Kuglitsch, Alexander.Watkins\}@colorado.edu
}

\begin{abstract}
This paper discusses the specialized instructional needs of creative practitioner communities and consequent tensions students of applied fields face related to their place in the academy. By drawing on the literature of workplace information behavior and exploring the multiple communities of practice that creative practitioners navigate, we suggest information literacy approaches that acknowledge and accommodate their unique needs. If librarians acknowledge an inherent multidisciplinarity, wide ranging use of sources, tacit knowledge, and information use in specialized creation spaces, they can teach information literacy skills that are transferable and meet workplace affordances and needs. This leads to information literacy instruction that resonates with students in these fields and positions them to better succeed in their chosen fields.
\end{abstract}

Keywords: Professional information literacy $\cdot$ Workplace information literacy Practice-based research $\cdot$ Learning spaces $\cdot$ Practitioner communities

\section{Introduction}

The specialized instructional needs of creative practitioner communities in academiathe people who apply knowledge to create things, whether art, buildings, or bridges - is frequently neglected in information literacy instruction. Often, library instruction conflates the needs of this group with the needs of traditional scholars. Yet the research necessary for writing an academic paper is markedly different from the research that goes into creating an object or design. Strict adherence to a purely academic approach fails to serve students who will encounter very different norms in their future workplaces, and leads to the impression that information literacy is irrelevant for practitioners' future careers. This can easily demotivate students. A shift to understanding the unique needs and approaches in the applied fields will lead to richer and more effective instruction and outreach to practitioners.

At the same time, the academy tends to silo design and making activities in engineering and in the arts. But phenomenographic evidence suggests that the experience of design is not so different across fields as our academic structures imply [1]. Consequently, we believe that information behaviors across fields can be compared to develop a better understanding of literacy needs across design fields for future success 
in the workplace. In this paper, we take a broader approach to design practitioner's needs and review the literature of information behavior of these groups in order to apply it to student information literacy needs. To do this, we will first review research and information behaviors of practitioner communities, demonstrating similarities across applied fields, and then explore the implications for information literacy instruction.

\section{Research for Practitioners}

We examine practitioners as a group, ranging from artists to engineers, who nevertheless share research commonalities rooted in the applied nature of their studies. Students in these fields are engaged in a praxis that combines theory with practice. A similar cycle of research-design-build (or create) applies across the group: a studio artist might research a concept, theory or art movement that will inspire their work; architects may do extensive precedent research to inform their design; an engineer might research basic physics concepts to apply to a design. Practitioners in these fields are engaged in reflection about the role of inquiry in design as well, examining the difference between researching for design and design as research. The architecture field is questioning the division that exists between research and practice, and arguing that design practice can also be a way of creating new knowledge [2]. In art practice there is a recurrent debate about whether artists do research: is art a form of inquiry? Critics question whether art is a valid research product or the studio is a valid site for research, yet, "if research is the creation of new knowledge, then the outcome is not merely to help explain things in causal or relational terms, but to fully understand them in a way that helps us act on that knowledge [3]". Because of this move to practice-based research there is an increasing expectation that art students be able to conduct research that is accepted in both the art and academic worlds [3]. Despite the popular conception of engineering as a cut and dried rule-based field, engineers operate in a complex, ambiguous setting, calling for creative synthesis of ideas across fields to develop optimal designs [4]. In engineering, integrating research into design is essential to developing creative solutions to problems.

\subsection{Students Work in the Distinct Communities of Academics and Practitioners}

Students who are studying to become practitioners, whether they be engineers or artists, exist and work in two distinct but overlapping worlds. They move between a textually oriented academic world, where research leads to carefully constructed arguments, and the practitioner world, where research leads to embodied designs. This requires a shift from thinking about pieces of evidence in developing a rhetorical argument, to thinking about facts, constraints, and specifications as environmentally dependent. An engineer, for example, cannot simply identify a superconductor that meets the most basic needs for a project; they must identify a superconductor that will function within the realistic physical constraints of the project. This need to focus on the embodied output of research requires a different kind of evaluation in practice than it might in academic 
contexts. Yet as practitioners in the academy, students and faculty move between these two communities of practice, the academic sphere and that of their applied work, each with their own norms, jargon, information sources and requirements.

A central aspect of this is that students must learn to master their field's academic vocabulary and discourse, as well as a practitioner discourse. They are often taught by faculty members who may or may not have participated in the practitioner community and vice-versa; thus they frequently receive mixed messages about requirements. For example, artists need facility with the language of gallery announcements and artist's statements, often rendered in what has been labeled "International Art English" as well as with the theory and jargon laden world of art history research papers [5]. For engineers, architects, or environmental designers a familiarity with technical writing is needed as well as academic language. These students will need to write specifications, technical reports, professional presentations and pitches. Students in these fields will need to write to explain their designs to others who might implement them, to interest potential investors, and to explain how to use a design. Students of practice must be able to fluidly shift between academic and practitioner discourses in the course of a single school day.

Students will also need to move between two different worlds of information behavior. Tenopir and King, for example, note a longstanding difference in use of formal vs. informal communication channels between academic and applied communities in engineering [6]. In their academic work, students learn to privilege formal communication and rely heavily on journal and monographic literature. They are taught to identify academic authority, and to question the credibility of information that has not undergone peer-review. In the world of practice, students need to use informal communications to find the information they need. Grey literature, trade journals, internal documentation, blogs, social media, and personal communication are all key places practitioners find information.

Navigating these multiple communities of practice can be challenging but it is essential for students. By adopting the norms, language, and sources of students' applied as well as academic activities, library instruction can be more effective and relevant to students' future careers. Thus, a recognition of information behavior in practitioner communities underpins effective information literacy for these fields.

\subsection{Practitioner Research Relies on Varied Source Types}

The key source types in practitioner and academic contexts tend to be drastically different. Though practitioners sometimes use scholarly journals, they tend to find them excessively effortful and frequently out of date [6]. Engineering faculty, for example, rely heavily on journals as one of their top two information sources [7], while practitioners rely on standards and technical reports [8]. Practitioners, especially those in the art and design world rely on trade publications much more than academic publications that highlight new techniques and report on cutting edge art and design practice $[9,10]$. For engineers, trade publications are particularly important in the initial scoping and task clarification stage of design [11]. Architects frequently use a wide variety of source types, especially images and video; in one study watching online videos formed a key part of architects information gathering process [12]. For engineers information is 
accessed in a multiplicity of formats: not only text, but also drawings, photographs, prototypes or mockups, code, or simulations [4]. These varied information sources are particularly rich resources for inspiration and information about current and emerging methods for design. However, often in academic contexts only peer-reviewed journals are taught as acceptable sources, creating a conflict between research students need to perform for their academic work and for their practice. Library instruction is well suited to help practitioner students navigate the complex world of source types and when they would be useful, especially as they may receive mixed messages from their academic and practitioner instructors.

\subsection{Practitioner Research Draws from Multiple Disciplines}

Practitioner information seeking behavior is inherently interdisciplinary. Across creative and design fields, the ability to identify and assess another field's ideas and apply them in practice is key. Artists seeking information look at "an almost unlimited range" of source types and subjects [13]. Hemming finds that artist's needs are idiosyncratic, they need information with "no epistemic relationship to art [10]". Greer's citation analysis of undergraduate theses found that sources primarily about the fine arts represented just $26 \%$ of the citations [14]. Architects frequently use a wide range of online resources for inspiration, site information, and ideas about process [12]. In the authors' experience, architecture students need information from a wide variety of disciplines to successfully complete their designs. These range from architectural precedents to maps and GIS, local history, environmental research, social and psychological information, to health and wellness, and more.

Engineering is similar; to design an engineering solution, information may be drawn from disciplines across the fields of engineering, but also from other areas of design like graphic, architectural and industrial design, as well as the humanities and social sciences [4]. This is necessary because engineers must apply ideas from the sciences to a human context and produce an item for use. A civil engineer, for example, may require information about engineering methods, but also local geology, law, international standards, and construction management. While wide span of disciplines is not absent from academic engineering, it is particularly apparent in industry, where teams tend to work with specialists from a wide range of disciplines, bringing together many areas of expertise, a scenario that is rarely available to students in a classroom context [4].

\subsection{Practitioner Research Relies on Tacit Knowledge}

In applied fields, experts are often identified by their mastery of a craft and tacit knowledge, rather than solely by academic credentials. Students of practice must be able to recognize others - whether they be professors, project managers, lab managers, or other artists - as information resources, a skill that can be challenging to students trained only in an academic tradition [15]. Practicing artists frequently need to seek out communities of artists for information on materials and techniques and the art market [10]. Mason and Robinson identify an "invisible college" that is an important resource for emerging artists, both for career development (an area artists felt underprepared for 
by their schooling), as well as for artistic inspiration where they cited conversation and debate as key sources [13]. The architects in Makri and Warick's study frequently sought out their peers' blogs for ideas on their process and what they might do next [12].

Similarly, Allard et al. found that colleagues and team members are a fundamental information source for engineers, although consulting the internet as a first step has increased [16]. Even when using print sources like standards and technical reports, engineering practitioners combine them with tacit knowledge, consulting with colleagues to identify, interpret, and contextualize information [18]. Consulting with colleagues is a way to respond efficiently to active situations when using static technical reports, since colleagues can provide context for decisions and help with how to best apply the information [17]. Colleagues' tacit knowledge was particularly valued for several reasons: first, it was perceived as especially trustworthy; second, it tended to lead efficiently to hard to find documents; and third, colleagues were assumed to be able to validate practices or suggest someone who could [16]. Thus, for engineers even when using textual sources, tacit knowledge is used to enrich the text and make its use more efficient, and this approach is a common thread among practitioner fields.

\subsection{Practitioner Research Happens in Unique Spaces}

As well as commonalities of practice, these fields share a reliance on designated spaces for building and creation. Their unique spaces - labs, makerspaces and studios-have unique affordances for library outreach, and their own associated information-seeking behaviors that must be acknowledged in information literacy. These spaces of doing correlate with students' future workplaces, allowing information literacy learned in this context to be more easily transferred, consequently promoting critical and creative approaches in the workplace. Studios play a key role in artist's presentation of themselves and in many ways have a performative aspect [19]. They are the site of the all-important studio visits, when curators or dealers come by the artist's studio to evaluate their work for potential shows. Books and other research resources are a hallmark of artist's studios, but how much they are for use or for show is not clear. Labs, somewhat similarly, tend to have a small collection of frequently used works, but again, it is not clear how much they are used. Recent work around makerspaces has extensively discussed how to set them up in the library [20], particularly the public library, but relatively little work has been done about how information use occurs in them. By bringing books and information literacy instruction into these spaces it explicitly ties research to making, important because frequently practitioners class library research as belonging only to the academic side of their work.

\section{Understanding the Workplace Information Landscape}

As student practitioners move from their academic environment to their new workplace environment, they will find a drastically changed information landscape. In particular, students encounter information scarcity, time constraints, and an increased need to rely on their own personal collections of information. 
When artists move from university-provided studio to their own space, the available research resources drastically change. Emerging artists especially do not necessarily have the financial means to purchase all the books or subscriptions they may need to inform their research. Consequently, artists used several places to substitute for a university library including public libraries and bookstores. Artists and designers were just as likely to borrow a friend's copy of a magazine or read it in a bookstore rather than subscribe [13].

Engineers, too, find themselves in a dramatically different resource landscape. First, practicing engineers tend to work under tight time constraints and in a context where much information is proprietary [6]. Additionally, in the workplace it becomes particularly critical to match information needs with level of evaluation: the consequences for selecting the first few resources of a search are minimal in the paper-writing context, but significant in the design process [21]. Moreover, an engineering firm is more likely to provide just in time resources, unlike academic libraries that tend to lean more towards a just in case model, so students need to be comfortable finding information in such situations [8]. Engineers in practice frequently curate and rely on personal collections of information, so a familiarity with methods and tools that support this are key [17]. Understanding how to find information by multiple paths and quickly evaluate whether it is worth sinking their own or their companies resources into obtaining an item is key.

\section{Implications for Information Literacy Instruction}

Understanding practitioner information literacy needs is especially important for subject specialist librarians who serve practitioners in the arts and engineering, as these librarians mostly come from an academic rather than practitioner educational background. Consequently, they may not be attuned to the unique needs of practitioner students. Indeed $63.2 \%$ of art librarians have an undergraduate degree in art history or other humanity, compared to just $20.8 \%$ who have a studio art or architecture background. Of the non-LIS advanced degrees held by art librarians $72.8 \%$ were in art history or another humanity compared to $12.8 \%$ in studio art or architecture [22]. The situation is still more mismatched in STEM. In a 2000 survey of science librarians, $32.2 \%$ had some kind of science undergraduate degree at all, only $3.3 \%$ had an engineering undergraduate degree, and only $8.9 \%$ had an advanced degree in any area of the sciences or engineering [23]. Thus, librarians in such fields may be apt to fall back on academic information literacy models in contexts where a more applied model is appropriate. It is therefore important for librarians to be aware of their own assumptions about user needs, and to actively work to address the needs of practitioners in their library instruction.

\subsection{Information Literacy Instruction for Students Moving Between Academic and Practitioner Communities}

Librarians need to recognize that students are moving between practitioner and academic worlds, each with different requirements for research. For example, library 
instruction that focuses on authority codified in peer review and academic credentials can have the effect of minimizing the importance of key practitioner sources such as trade journals, grey literature, blogs, or technical reports. Librarians should teach students about multiple sources of information spanning academic and practitioner communities. By teaching students about the different affordances of various types of sources, we can help them see how these sources work synergistically to inform them about their field. We can show them how practitioner knowledge can be useful for academic writing and how academic knowledge can be useful for their practice. Ideally this will both familiarize them with the important information sources of their future workplaces, as well as demonstrate the continuing usefulness of academic knowledge to their practice.

\subsection{Information Literacy Instruction for Multidisciplinary Research}

Librarians' academic training may lead them to ignore practitioners' inherently multi-disciplinary and wide-ranging research needs. Academic research typically relies on the information sources and tools of a single discipline. But the needs of practitioners demand library instruction that encompasses a broader range of resources and databases. Librarians should not assume that practitioner students only need to know the primary databases in a specific academic field, but rather should expect that students will want and need to explore the literature of several disciplines. This might include teaching architectural design databases to architectural engineers, teaching social science databases to architects, or showing artists how to navigate philosophy resources. Frequently, instruction to practitioners will also require a willingness to engage with uncommon types of sources. Students from across the spectrum of design and practice may need to be taught to look at materials collections, product catalogs, patents, images, or videos.

\subsection{Information Literacy Instruction and Tacit Knowledge}

Librarians need to recognize and infuse respect for tacit knowledge into the classroom. By discussing the idea that authority is contextual and that authority and knowledge can come in many flavors, librarians can expose the importance of tacit knowledge. Ideally, librarians would provide examples of tacit knowledge as expert knowledge: master artisans, laboratory technicians, and makerspace machinists. Authority in this context is often validation through social means. Practitioners want knowledge that has proved successful in practice and is validated by others' firsthand experience. Considering the degree to which designers rely on community tacit knowledge, this is an essential skill. As well as explicitly discussing the idea of tacit and practitioner knowledge, librarians can encourage the development of note and record keeping structures that track local experts, as designers and engineers might do in practice. Librarians also might consider encouraging research consultations by framing them as consulting the tacit knowledge of an information professional. By acknowledging and validating the extremely social nature of information seeking in practitioner fields, librarians can develop trust with students in practitioner fields and prepare them to navigate the social aspects of information seeking they will encounter. 


\subsection{Bringing Information Literacy into Practitioners' Spaces}

In the working world, students will frequently encounter research needs, but meeting those needs will relatively rarely take place in a formal library setting. Reaching out to students in their spaces helps set the expectation that research is not only an academic pursuit. Teaching for future workplace environments can encompass teaching outside of the library and in students' spaces. By bringing instruction and outreach into student practitioner spaces such as studios, makerspaces and laboratories, librarians can naturalize the idea of research being integrated in multiple phases of design and production, as well as mimic a workplace context. There has recently been an increasing recognition that information literacy instruction for artists should extend to the studio, especially by attending studio critiques, because the librarian presence in this setting reinforces the connection between the artistic process and the research process [24, 25]. This has the potential to prepare students for a workplace environment where they must talk fluently about their work and how it fits in existing artistic conversations during all important studio visits by curators and gallerists. A similar situation applies in engineering; in the author's experience going out to engineering lab groups, attending poster presentations, and reaching out to engineers in their own spaces normalizes information seeking as part of the design process. Engineers in both the academy and in practice rarely rely on physical library materials, removing one avenue to outreach, but by being present in the spaces engineers use, librarians can demonstrate the importance of information literacy in engineering. Librarians bringing information literacy into practitioner spaces can increase awareness and relevancy of this learning to student's future workplace environments.

\subsection{Integrating Information Literacy in the Design Process}

Explicitly teaching information literacy and research as threaded throughout the design process is important. When possible, it would be best to teach different skills needed at different points of the design process at the point of need. But for librarians who only have one opportunity to visit a class, it is especially important to model integrating research into multiple design phases. For example, students could map their design process, and the types of information they might need at each stage: identifying a problem, imagining a design, investigating execution, and producing the design. This might adhere to one of the many prescriptive models of design that are explicitly taught in engineering schools, like Radcliffe's Information-Rich Engineering Design, or it might be a more free-flowing process that allows students to define their own model of design $[4,11]$. Regardless of how research is integrated throughout the design process, that it happens is necessary for students to learn how to function in the workplace, results in more authentic learning, and in better design outcomes [11].

\subsection{Changing Access to Information}

It is especially important to acknowledge practitioners' impending loss of access to information after they graduate in teaching transferable information literacy skills. For many students in academic fields, losing access to library resources is unfortunate but 
does not have a direct bearing on their post-university work. On the other hand, practitioner students will be attempting to directly apply the skills and processes they learned in school to their career. Librarians should specifically teach how to conduct research without academic affiliations and to emphasize tools that practitioners will still have access to. Librarians should also pay particular attention to teaching information management; when intellectual resources represent fiscal and temporal resources, and when students must curate and develop their own personal libraries, as they do in practice, it is especially important to have efficient management systems [17]. By giving practitioners the skills to adapt their research practices to this changed environment we can empower them to continue to use these skills, rather than having them feel that research can no longer be part of their practice in their present situation.

\subsection{Intellectual Property}

Finally, it is important to address intellectual property. Students in practitioner fields must understand how rights and responsibilities change as a student and as a professional. In the academic context, fair use, copyright, and citation are the most commonly explored aspects of intellectual property, but the world of practice is complicated by patents, trademarks, and trade secrets. Patents and trade secrets are a direct contrast to the academic context where ideas are shared in order to establish primacy; in practice, ideas may be hidden in order to capitalize on them. Consequently, students need to know professional conventions and norms, both for themselves as users of others' intellectual property and to support the creation and safeguarding of their own intellectual property. An engineer, for example, needs to know how to protect their own work with patents-but also to know that perhaps a completed patent is the best source for up to date information [11]. Moreover, a patent is not only potentially the best source of up to date information, resources such as USPTO and Espacenet are freely available sources of detailed technical information.

As well as managing more options for protecting intellectual property, the more permissive standards for fair use in academic contexts may not apply to practitioners in the workplace. So, it is important that instruction equips students not just with how they can use other's work in academic contexts but in future professional situations as well. Yet at the same time as fair use becomes less permissive, there can be more permissive standards for credit-sharing; a student providing a full bibliographic citation of a design inspiration rather than an informal hat tip in a pitch PowerPoint might look out of touch. Consequently, learning to navigate credit-sharing informally is important for professional growth.

\section{Conclusion}

The ability to transfer information literacy between realms - whether personal, workplace, or academic - is key for students to develop their lives as they want to and to developing an intrinsically motivated understanding of information literacy. In particular in the United States, but increasingly elsewhere, there is a growing tension between university education as vocational preparation and as a purely intellectual 
endeavor. Especially as students are facing serious financial challenges to attend college and university, a focus on the purely academic can come to seem like a luxury leading to a shift of focus to applied education. But the ability to pursue intellectual questions and lifelong learning should not be reserved for the privileged alone. By linking information literacy to the future careers of practitioners, librarians can give students both the practical skills they need to succeed after graduating while also empowering students in intellectual exploration and the pursuit of knowledge.

\section{References}

1. Daly, S.R., Adams, R.S., Bodner, G.M.: What does it mean to design? A qualitative 1nvestigation of design professionals' experiences. J. Eng. Educ. 101, 187-219 (2012)

2. Hensel, M., Nilsson, F. (eds.): The Changing Shape of Practice: Integrating Research Anddesign in Architecture. Routledge, New York (2016)

3. Sullivan, G.: Research acts in art practice. Stud. Art Educ. 48, 19-35 (2006)

4. Radcliffe, D.F.: Multiple perspectives on engineering design. In: Integrating Information into the Engineering Design Process, pp. 7-19. Purdue University Press (2014)

5. Rule, A., Levine, D.: International Art English. https://www.canopycanopycanopy.com/ contents/international_art_english

6. Tenopir, C., King, D.W.: Engineer' information seeking and use. In: Communication Patterns of Engineers. Wiley, Hoboken (2004)

7. Engel, D., Robbins, S., Kulp, C.: The information-seeking habits of engineering faculty. Coll. Res. Libr. 72, 548-567 (2011)

8. Waters, N., Kasuto, E., McNaughton, F.: Partnership between engineering libraries: identifying information literacy skills for a successful transition from student to professional. Sci. Technol. Libr. 31, 124-132 (2012)

9. Snow, C.: Architects' wants and needs for information, demonstrated through a universitybased information service. In: AP, vol. 27, pp. 112-123 (1975)

10. Hemmig, W.: An empirical study of the information-seeking behavior of practicing visual artists. J. Doc. 65, 682-703 (2009)

11. Radcliffe, D.F.: Information-rich engineering design. In: Integrating Information into the Engineering Design Process, pp. 46-57. Purdue University Press (2014)

12. Makri, S., Warwick, C.: Information for inspiration: understanding architects' information seeking and use behaviors to inform design. J. Am. Soc. Inform. Sci. Technol. 61, 17451770 (2010)

13. Mason, H., Robinson, L.: The information-related behaviour of emerging artists and designers: inspiration and guidance for new practitioners. J. Doc. 67, 159-180 (2011)

14. Greer, K.: Undergraduate studio art information use: a multi-school citation analysis. Art Doc.: Bull. Art Libr. Soc. N. Am. 35, 230-240 (2016)

15. Head, A.J.: Learning curve: how college graduates solve information problems once they join the workplace. Project Information Literacy, Passage Studies Research Report (2012)

16. Allard, S., Levine, K.J., Tenopir, C.: Design engineers and technical professionals at work: observing information usage in the workplace. J. Am. Soc. Inform. Sci. Technol. 60, 443 454 (2009)

17. Fosmire, M.: Ways that engineers use design information. In: Integrating Information into the Engineering Design Process, pp. 35-43. Purdue University Press (2014)

18. Hertzum, M., Pejtersen, A.M.: The information-seeking practices of engineers: searching for documents as well as for people. Inf. Process. Manag. 36, 761-778 (2000) 
19. Jacob, M.J., Grabner, M. (eds.): The Studio Reader: On the Space of Artists. School of the Art Institute of Chicago: University of Chicago Press, Chicago (2010)

20. Willett, R.: Making, makers, and makerspaces: a discourse analysis of professional journal articles and blog posts about makerspaces in public libraries. Libr. Q. 86, 313-329 (2016)

21. Fosmire, M.: Information literacy and lifelong learning. In: Integrating Information into the Engineering Design Process, pp. 22-34. Purdue University Press (2014)

22. Brinkman, S.: Census of Art Information Professionals: Preliminary Report of Findings. ARLIS/NA (2017)

23. Winston, M.D.: Academic science and engineering librarians: a research study of demographics, educational backgrounds, and professional activities. Sci. Technol. Libr. 19, 3-24 (2000)

24. Petraits, E.: Assessing the impact of library instruction on studio-based research: developing a qualitative model. Art Libr. J. 42, 80-85 (2017)

25. Garcia, L., Peterson, A.: Who invited the librarian? Studio critiques as a site of information literacy education. Art Libr. J. 42, 73-79 (2017) 